\title{
FINTECH AND INDUSTRIAL REVOLUTION 4.0, THE IMPACT ON THE FINANCIAL WORLD
}

\author{
Hoàng Hà \\ University of Economics - The University of Danang \\ Email: hahoang@due.edu.vn
}

\begin{abstract}
Industrial Revolution 4.0 is taking place strongly and has gained a lot of special attention from the public recently. For the financial world, this revolution has given birth to Fintech - a generation of start-up companies with advanced technology based on the Internet. Most Fintech companies start out with payment services, but in many other areas of the financial world, by their own strategies, Fintech is competing directly or indirectly with segments that are the monopoly of traditional financial services such as capital mobilization, lending, asset management, etc.

The results show that Fintech has had a tremendous impact on the financial world and traditional financial institutions. However, the challenges and risks of this start-up generation should not be taken seriously and neglected their positive impacts such as promoting innovation, increasing competition, better serving customers. We also believe that Fintech will be a promising land for startups in Vietnam. As many studies in the world have shown, the goverment need to observe closely, but should not lay down rules too soon or too closely because it can extinguish a field that has many advantages for Vietnam in the 4.0 revolution. This is also an important citation for further research in this field in Vietnam.
\end{abstract}

Keywords: Start-up, Fintech, Industrial Revolution 4.0, Sharing Economy

\section{FINTECH VÀ CÁCH MẠNG CÔNG NGHIỆP 4.0, NHŨNG TÁC ĐộNG LÊN THẾ GIỚI TÀI CHÍNH}

\section{TÓM TÄT}

Cách mạng công nghiệp 4.0 đang diễn ra mạnh mẽ và nhận được nhiều sự quan tâm đặc biệt của dư luận trong thời gian gần đây. Đối với thế giới tài chính, cuộc cách mạng này đã khai sinh ra một thế hệ start-up mới mang tên gọi chung là Fintech - các công ty khởi nghiệp bằng công nghệ tiên tiến dựa trên nền tảng Internet. Hầu hết các công ty Fintech khởi nghiệp với dịch vụ thanh toán, tuy nhiên ở nhiều lĩnh vực khác trong thế giới tài chính, bằng những chiến lược riêng của mình, Fintech đang cạnh tranh gián tiếp hoặc trực tiếp với những mảng vốn là độc quyền của các ngành dịch vụ tài chính truyền thống như huy động vốn, cho vay, quản lý tài sản...

Kết quả nghiên cứu cho thấy Fintech trong thời gian đây đã có những tác động to lớn lên thế giới tài chính và các định chế tài chính truyền thống. Tuy nhiên, không nên quá xem trọng những thách thức và rủi ro từ thế hệ start-up này gây ra và coi thường những tác động tích cực như thúc đẩy đổi mới, cạnh tranh, giúp phục vụ khách hàng tốt hơn. Ngoài ra chúng tôi cho rằng Fintech sẽ là một miền đất hứa với khởi nghiệp tại Việt Nam. Đồng thời như nhiều nghiên cứu trên thế giới đã chỉ ra, các nhà quản lý cần theo dõi sát sao nhưng không nên đưa ra các quy định quá sớm hoặc quá chặt chẽ, có thể dập tắt một lĩnh vực mang lại nhiều lợi thế cho Việt Nam trong cuộc cách mạng 4.0. Đây cũng là một cơ sở trích dẫn quan trọng cho những nghiên cứu tiếp theo trong lĩnh vực này tại Việt Nam.

Tù khóa: Khởi nghiệp, Fintech, Cách mạng công nghiệp 4.0, Start-up, Kinh tế chia sẻ 


\section{Giới thiệu}

Khái niệm Cách mạng công nghiệp 4.0 (CMCN 4.0) được giới thiệu lần đầu tiên bởi viện nghiên cứu Fraunhofer-Gesellschaft và chính phủ liên bang Đức như một sự kết hợp giữa Internet Vạn vật (IOT), hệ kết nối không gian số - thực thể (CPS) và các dịch vụ Internet tự vận hành giữa chúng với nhau và với con người trong cùng một hệ thống (Kagermann, H. et al, 2013).

Với tốc độ đột phá của $\mathrm{CMCN} 4.0$ được đánh giá "không có tiền lệ lịch sử" trong tương quan với các cuộc $\mathrm{CMCN}$ trước đây, $\mathrm{CMCN} 4.0$ đang tiến triển theo một hàm số mũ chứ không phải là tốc độ tuyến tính. Mặt khác, nó đang phá vỡ hầu hết ngành công nghiệp ở mọi quốc gia. Và chiều rộng và chiều sâu của những thay đổi này báo trước sự chuyển đổi của toàn bộ hệ thống sản xuất, quản lý và quản trị. Kéo theo đó là những cơ hội cực kỳ to lớn mang tính biến chuyển nền tảng cho việc mang lại những sản phẩm dịch vụ tài chính mới trên nên tảng công nghệ. Từ đó người tiêu dùng sẽ được tiếp cận với các dịch vụ tài chính dễ dàng hơn, thuận tiện hơn với một chi phí rẻ hơn (Schwab, K., 2017)

Tận dụng được những thế mạnh về công nghệ, nhiều công ty khởi nghiệp trong lĩnh vực Fintech đã có sự xuất phát sớm hơn các định chế tài chính như ngân hàng để đưa ra các nền tảng trên internet nhằm cạnh tranh trực tiếp. Về phía người tiêu dùng, hiện tại với cơ cấu dân số trẻ như Việt Nam và sự phổ cập của các thiết bị thông minh như smartphone, máy tính cá nhân..., họ tỏ ra khá hào hứng trong việc đón nhận sự đổi mới này. Có thể cô đọng lại, đây là thời điểm chín mùi cho sự trỗi dậy của Fintech và thế giới đang chứng kiến những tác động chưa từng có tiền lệ trong ngành tài chính ngân hàng vốn có lịch sử tồn tại từ rất lâu đời.

Nghiên cứu này được thực hiện nhằm tìm hiểu những tác động của Fintech lên thế giới tài chính và các định chế tài chính truyền thống như ngân hàng. Từ đó đưa ra những khuyến nghị và giải pháp mang tính gợi ý để các bên, trong đó có cả cơ quan quản lý, có thể tham khảo nhằm có những hành động phù hợp. Nếu tận dụng những lợi thế của cuộc $\mathrm{CMCN} 4.0$ trong thế giới tài chính, khách hàng sẽ được quan tâm và phục vụ tốt hơn, như vậy lợi ích của các bên có liên quan cũng sẽ được đảm bảo theo hướng tích cực nhất.

\section{Cơ sở lý thuyết và phương pháp nghiên cứu}

\subsection{Co' sở lý thuyết}

\subsubsection{Cách mạng công nghiệp 4.0}

Chúng ta đang chứng kiến cuộc $\mathrm{CMCN} 4.0$ diễn ra. "Cách mạng công nghiệp đầu tiên sử dụng năng lượng nước và hơi nước để cơ giới hóa sản xuất. Cuộc cách mạng lần 2 diễn ra nhờ ứng dụng điện năng để sản xuất hàng loạt. Cuộc cách mạng lần 3 sử dụng điện tử và công nghệ thông tin để tự động hóa sản xuất. Bây giờ, cuộc Cách mạng Công nghiệp Thứ tư đang nảy nở từ cuộc cách mạng lần ba, nó kết hợp các công nghệ lại với nhau, làm mờ ranh giới giữa vật lý, kỹ thuật số và sinh học" (Stock, T., \& Seliger, G., 2016). Trong cuộc cách mạng này, khả năng kết nối giữa hàng tỷ con người bằng điện thoại thông minh, cùng với khả năng lưu trữ và tiếp cận trí thức có thể thể nói là vô hạn và chưa từng có lịch sử đang diễn ra. Những khả năng này còn được nhân lên nhiều lần bởi những công nghệ đột phá trả nhiều lĩnh vực như trí tuệ nhân tạo, rô bốt, Internet vạn vật, xe tự lái, in 3D, công nghệ nano, công nghệ sinh học, khoa học vật liệu, lưu trữ năng lượng và máy tính lượng tử (Schwab, K., 2017).

Tại Việt Nam, CMCN 4.0 nhận được sự quan tâm rất lớn từ chính phủ. Gần đây nhất vào tháng 5 năm 2017, Thủ tướng Nguyễn Xuân Phúc đã ban hành Chỉ thị 16 "Về việc tăng cường năng lực tiếp cận cuộc cách mạng công nghiệp lần thứ 4 ” thể hiện sự chủ động trong việc nắm bắt và đón đầu các 
làn sóng đổi mới về công nghệ trên thế giới. Tại Chỉ thị này, một loạt các Bộ cũng được Thủ tướng giao trọng trách, với mục tiêu làm sao để Việt Nam không bị tụt hậu so với thế giới ở cuộc cách mạng này. (Chỉ thị 16, 2017)

Trong triển lãm quốc tế về phát triển công nghiệp thông minh (Smart Industry World 2017) lần đầu tiên tổ chức tại Việt Nam dưới sáng kiến của Ban Kinh tế Trung ương Đảng, Thứ Trưởng Bộ Công Thương Việt Nam Đỗ Thắng Hải thừa nhận “Cả các nhà quản lý và doanh nghiệp Việt Nam đều đang lo lắng với cách mạng công nghiệp 4.0 vì cuộc cách mạng này ảnh hưởng tới nhiều lao động. Các chuyên gia đánh giá hơn $80 \%$ lao động sẽ bị ảnh hưởng trong khi Việt Nam lại là nước đang thâm dụng nhiều lao động” (Tư Giang, 2017)

Công nghệ cao vượt trội từ cuộc $\mathrm{CMCN} 4.0$ mang lại đang tác động rất mạnh vào ngành ngân hàng và các định chế tài chính truyền thống và được dự báo sẽ mang lại sự thay đổi toàn diện ngành tài chính nói chung trong thời gian tới.

\subsubsection{Fintech là gì}

Fintech trong tiếng Anh là từ ghép từ hai chữ cái đầu của "Financial", thuộc về lĩnh vực tài chính hay trong lĩnh vực tài chính và "Technology", nghĩa là công nghệ. Mặc dù Fintech chỉ mới đang ở trong giai đoạn đầu phát triển, chúng được kỳ vọng sẽ định nghĩa và định dạng lại tương lai của ngành công nghiệp tài chính.

Ngân hàng thương mại, ngân hàng đầu tư, môi giới chứng khoán, quỹ tương hỗ và sàn giao dịch chứng khoán hình thành nên nền tảng của nền tài chính hiện đại. Bất chấp những mối liên kết chặt chẽ đã được tạo ra, những công ty khởi nghiệp đổi mới vẫn không ngừng nỗ lực để tạo ra những sự thay đổi mang tính nền tảng, xóa bỏ những liên kết tài chính hiện hữu để tách ra thành những ốc đảo tài chính mới (Lin, T. C., 2015).

Cuộc khủng hoảng tài chính toàn cầu diễn ra năm 2008 được nhiều nhà nghiên cứu cho là bước ngoặt đối với kỷ nguyên tài chính mới tạo ra bởi Fintech. Chính cuộc khủng hoảng này cũng là chất xúc tác quan trọng khi nhận thức của công chúng về sự ổn định của các ngân hàng bị thay đổi, mức độ tin tưởng đối với việc xử lý các dịch vụ tài chính bị lung lay. Ngày càng nhiều công ty ở các quốc gia phát triển cũng như đang phát triển tiến hành các dịch vụ tài chính cung cấp tiền và được sự ủng hộ của khách hàng nhờ sự thuận tiện và chi phí rẻ hơn các dịch vụ tài chính truyền thống. Như vậy danh tiếng cũng không là yếu tố có ý nghĩa quyết định đối với việc lựa chọn nơi cung cấp các dịch vụ tài chính. Lập luận này cũng được minh chứng trong một nghiên cứu về sự hài lòng của khách hàng đối với dịch vụ cho vay tiêu dùng, thực hiện năm 2014 của Trần Thị Hiền Dung. Trong kết quả tìm được, đáng lưu ý đó là giá cả (thể hiện bằng lãi suất đi vay) có hệ số hồi quy chuẩn hóa lớn nhất trong các nhân tố tác động lên sự hài lòng của khách hàng (Độ tin cậy, giá cả, tính đảm bảo và tính thuận tiện). Nghiên cứu này đưa ra kết luận lãi suất cho vay có vai trò vô cùng quan trọng trong giai đoạn suy thoái kinh tế như hiện nay.

Theo nhận định của nhóm nghiên cứu, Fintech có thể tái định hình ngành tài chính, tác động rất mạnh đến các thành phần quan trọng nhất của ngành này. Hiện tại các công ty cho vay P2P (Peer-toPeer lending)- mảng được đánh giá là mạnh nhất của Fintech giúp kết nối trực tiếp người đi vay với người cho vay dựa trên nền tảng Internet, đã hoạt động khá hiệu quả, giúp rút ngắn thời gian phê duyệt các khoản vay từ vài tuần ở các ngân hàng truyền thống xuống chỉ còn vài giờ.

Fintech tác động tích cực đến xã hội bằng cách gia tăng sự cạnh tranh, giảm chi phí cho khách hàng. Cung cấp dịch vụ tài chính cho những người có nhu cầu nhưng không được đáp ứng bởi ngân hàng truyền thống. Theo con số thống kê ước tính cho thấy $38 \%$ dân số thế giới không có tài khoản ngân hàng chính thức và trong số những người đang có tài khoản, hơn $40 \%$ chưa được đáp ứng đầy đủ 
nhu cầu vốn, đây là một thị trường khổng lồ đầy tiềm năng cho thế hệ công ty tài chính mới dưới tên gọi Fintech.

Tại Việt Nam, chúng tôi cho rằng Fintech đã và đang nhận được nhiều sự quan tâm của chính phủ và các cơ quan quản lý. Cụ thể, từ năm 2008, Ngân hàng Nhà nước (NHNN) đã nghiên cứu và cho phép nhiều công ty không phải là ngân hàng cung ứng dịch vụ thanh toán trên cơ sở thí điểm nhằm đáp ứng nhu cầu phát triển của thị trường. Đến nay, sau khi thiết lập khuôn khổ pháp lý tương đối rõ ràng, NHNN đã cấp phép hoạt động chính thức cho 20 tổ chức cung ứng dịch vụ trung gian thanh toán. Bên cạnh những loại hình Fintech trong lĩnh vực thanh toán, Việt Nam còn có những doanh nghiệp khởi nghiệp hoạt động trong lĩnh vực khác như: gọi vốn, dịch vụ cho vay trực tuyến, chuyển tiền, quản lý dữ liệu tài chính cá nhân (Nguyễn Kim Anh, 2017).

\subsection{Phưong pháp nghiên cúu}

Là một lĩnh vực còn tương đối mới mẻ, do đó số lượng các công trình nghiên cứu trong lĩnh vực này còn chưa nhiều trên thế giới, nhất là tại Việt Nam. Trong bước đầu tiên tiến trình nghiên cứu, chúng tôi tiến hành rà soát và tổng hợp các công trình nghiên cứu nổi bật về Fintech trên thế giới trong thời gian qua nhằm xây dựng một nền tảng cơ sở lý thuyết vững chắc giúp hiểu rõ bản chất của Fintech là gì. Tiếp tục, các thông tin trên các phương tiện thông tin và báo chí cũng được cập nhật và làm cơ sở cho nghiên cứu vì chúng tôi cho rằng, $\mathrm{CMCN} 4.0$ nói chung và Fintech nói riêng đang biến đổi từng ngày nên để kết quả nghiên cứu có tính thực tiễn, việc thu thập thông tin thực tế không thế bị xem nhẹ.

Chúng tôi sử dụng kết quả nghiên cứu của nhóm tác giả Hoàng Hà, Trần Đình Uyên (2017), khảo sát nhận thức của khách hàng về một sản phẩm của Fintech, hình thức cho vay ngang hàng trực tuyến (Peer-to-peer lending online). Căn cứ vào kết quả thu được từ gần 150 người tham gia trả lời, nghiên cứu trên đã chỉ ra được ba điểm mới trong nghiên cứu về cho vay ngang hàng nói riêng và thế giới tài chính Fintech nói chung. Thứ nhất, Tại Việt Nam nói chung và Đà Nẵng nói riêng, tiềm năng của cho vay ngang hàng trực tuyến và Fintech là rất lớn bởi nhu cầu và sự ủng hộ của người tiêu dùng khi có thêm các lựa chọn bên cạnh ngân hàng và các dịch vụ tài chính truyền thống. Thứ hai, Fintech vừa là cơ hội cũng vừa là đe dọa đối với ngành ngân hàng truyền thống. Tuy nhiên, cơ hội vẫn nhiều hơn là đe dọa. Một khi mô hình truyền thống thừa nhận những ưu điểm của mô hình mới này và cùng kết hợp để phục vụ các phân khúc bị bỏ quên của thị trường thì lợi ích của cả hai và lợi ích của người tiêu dùng cùng được đảm bảo. Thứ ba, kết quả khảo sát cho thấy quan điểm của người khảo sát về sự ủng hộ cho thấy, gần như có sự tương đồng về tỷ lệ những người được hỏi tin rằng cơ quan quản lý sẽ ủng hộ và ngược lại, cho rằng cơ quan quản lý sẽ hạn chế mô hình mới này. Điều này phản ánh đúng thực tế tại Việt Nam và là cơ sở hưu ích cho các nghiên cứu sâu hơn.

Trong bước cuối cùng, chúng tôi tiến hành phân tích sâu những dữ kiện đã thu thập được nhằm tìm câu trả lời cho nghiên cứu này và là cơ sở để đưa ra các đánh giá và thảo luận.

\section{Kết quả và đánh giá}

\subsection{Kết quả}

\subsubsection{Fintech và CMCN 4.0 có tác động thúc đẩy đổi mói mạnh mẽ trong ngành tài chính}

Dựa trên những ưu điểm vượt trội của mình trong khả năng đổi mới và tiếp cận công nghệ, Fintech theo quan điểm của chúng tôi đang thực sự đang giúp các thị trường tài chính và các hệ thống 
trên đó hoạt động hiệu quả hơn, phục vụ được nhiều đối tượng khách hàng hơn. Với khả năng tự động hóa và xử lý linh hoạt, các giao dịch tài chính thông qua Fintech trở nên nhanh chóng và đơn giản, từ đó tạo nên một áp lực đổi mới rất lớn đối với toàn ngành tài chính. Đặc biệt với một đất nước có cơ cấu dân số trẻ cao như Việt Nam và tỷ lệ phổ cập của thẻ ngân hàng và đặc biệt là thẻ tín dụng chưa cao, sự nổi lên của Fintech đã gia tăng cạnh tranh, giảm chi phí và giúp cho những người nằm ngoài vùng phủ sóng của ngân hàng có thể tiếp cận được các nguồn tài chính cần thiết.

Theo nghiên cứu của Phạm Xuân Hòe (2017), dưới áp lực cạnh tranh và đổi mới, 96\% các ngân hàng tại Việt Nam đã tìm hiểu về CMCN 4.0 qua các kênh khác nhau như: $84 \%$ thông qua phương tiện truyền thông, $48 \%$ qua các khách hàng và đối tác quen biết, $16 \%$ thông qua công ty tiếp thị sản phẩm. Đặc biệt, đầu tư đổi mới công nghệ và phát triển kênh bán hàng qua công nghệ số là những trụ cột chính trong chiến lược phát triển của các ngân hàng. Cụ thể $92 \%$ ngân hàng đang có những chuẩn bị về đầu tư đổi mới công nghệ và phát triển kênh bán hàng qua công nghệ số để đón nhận và thích ứng với những bước tiến của $\mathrm{CMCN} 4.0 \mathrm{~m} 76 \%$ chuẩn bị về thu hút lao động trong lĩnh vực kỹ thuât - công nghệ cao và công nghệ thông tin, $44 \%$ phát triển nguồn tài chính và sắp xếp lại mô hình chi nhánh, phòng giao dịch. Ngoài ra VIB còn chú trọng đến vấn đề số hóa các nghiệp vụ lõi của ngân hàng.

Tỉ lệ người sở hữu tài khoản ngân hàng ở Việt Nam mới ở mức $20 \%$ và số người có thẻ tín dụng chỉ là $3 \%$. Vì vậy Việt Nam vẫn là một thị trường rất hấp dẫn cho các công ty dịch vụ tài chính mới, nhất là khi dân số trong nước ở mức trẻ cùng nhu cầu kết nối cao. Những xu hướng này đại diện cho một cơ hội thực sự cho các công ty đang cung cấp mô hình kinh doanh dựa trên nền tảng kỹ thuật số.

\subsubsection{Fintech là một thách thức đối với các định chế tài chính truyền thống}

Với khả năng tối ưu hóa trải nghiệm người dùng, Fintech được dự báo sẽ mang đến không ít thách thức cho các ngân hàng truyền thống và cả ngành tài chính. Theo dự đoán của McKinsey, 10 $40 \%$ lợi nhuận ngành này sẽ bị đe dọa do sự bùng nổ của Fintech thúc đẩy quá trình số hóa, tất yếu dẫn đến sự giảm giá dịch vụ. Những tiến bộ của Fintech có thể mở rộng ngân hàng số đến 1,6 tỷ người trong các quốc gia đang phát triển và gia tăng tổng tín dụng cho cá nhân và doanh nghiệp lên tới 2,1 nghìn tỷ đô la vào năm 2025 (Manyika et al, 2016).

Theo nghiên cứu của nhóm tác giả Hoàng Hà, Trần Đình Uyên (2017), chiến trường chính giữa hai phía sẽ là cho vay tiêu dùng. Quan điểm này tương đồng với nghiên cứu của Balyuk (2016) khi tác giả cho rằng thị trường tín dụng cho vay tiêu dùng chiếm thị phần lớn nhất với ước tính lên tới 3,5 triệu tỷ đô la. Trong nghiên cứu được thực hiện tại Việt Nam, $65.3 \%$ người được phỏng vấn đồng ý với quan điểm cho vay tiêu dùng sẽ là thị trường lớn nhất trong cuộc cạnh tranh giữa Fintech và các định chế tài chính truyền thống, thị trường thứ hai với $51 \%$ lựa chọn là lĩnh vực cho vay tín chấp (phân biệt với vay tiêu dùng ở đặc điểm vay tín chấp không cần tài sản thế chấp đảm bảo). Trong hai lĩnh vực này, Fintech được cho là đang chiếm lợi thế hơn nhờ khả năng giải ngân nhanh, cùng với công nghệ và sử dụng các thuật toán cao cấp để tính lãi cho từng trường hợp khách hàng cụ thể. Ngoài ra với lợi thế về chi phí, các Fintech có thể đưa ra các mức lãi suất hấp dẫn hơn với các khách hàng vay tiền và người cho vay tiền. Đây cũng là những yếu tố các ngân hàng không thể bỏ qua bởi như các nghiên cứu được thực hiện tại Việt Nam đã chỉ ra ở trên, lãi suất là nhân tố tác động mạnh nhất đến quyết định chọn nơi gửi tiền hoặc vay tiền của khách hàng.

Trong một diễn biến đáng chú ý trong lĩnh vực ngân hàng, vào tháng 6 năm 2016, ngân hàng bán lẻ lớn nhất nước $\mathrm{Mỹ}$, Bank of America $(\mathrm{BoA})$ thông báo rằng họ sẽ cắt giảm khoảng 8.400 nhân sự trong tương lai gần. Theo tờ Fortune, số lượng khách hàng đi đến các chi nhánh thực tế của ngân hàng này giảm mạnh từ năm 2010, khiến cho nhà băng đã phải đóng cửa 1.200 chi nhánh trên toàn nước 
Mỹ. Lý do rất đơn giản, rất nhiều khách hàng sử dụng các dịch vụ của ngân hàng qua mạng thay vì đi đến tận nơi để giao dịch một cách truyền thống.

Financial Times cho rằng lý do của việc cắt giảm nhân sự này đến từ sự phát triển vũ bão của công nghệ và điều này thay đổi thói quen sử dụng các dịch vụ ngân hàng của người tiêu dùng. Điện thoại di động đang thay thế các giao dịch viên và các ứng dụng Fintech như mobile banking làm giảm nhu cầu đi đến chi nhánh để giao dịch.

Tại châu Âu, tình hình cũng không khá hơn với giới ngân hàng khi 8 ngân hàng hàng đầu của châu Âu đã sa thải khoảng 100.000 nhân viên vào đầu năm nay. Theo Blooomberg, những ngân hàng như: Barclays, Credit Suisse, Deutsche Bank và Standard Chartered đã mất khoảng 420 tỷ USD giá trị thị trường bởi sự lên ngôi của fintech khi những ứng dụng không bị kiềm hãm bởi luật lệ về tài chính như ngân hàng truyền thống ngoài hàng loạt biến động như lãi suất âm, sự chậm tăng trưởng của Trung Quốc, giá dầu thô giảm... (Lucinda Shen, 2016).

\subsubsection{Tiềm năng phát triển của Fintech tại Việt Nam là rất lớn}

FinTech đã nhận được rất nhiều sự quan tâm. Chỉ trong vòng 1 năm từ 2013 đến 2014, tổng đầu tư trên toàn cầu cho các công ty khởi nghiệp Fintech đã tăng 3 lần từ 4.05 tỷ USD lên 12.21 tỷ USD.

Trên thị trường hiện tại có khoảng 30 công ty Việt Nam tham gia vào sân chơi. Năm 2015, tổng cộng đã có 4,5 tỷ USD được rót vào 130 thương vụ trong khu vực này, trong đó Trung Quốc và Ấn Độ đứng đầu bảng.

Với dân số hơn 90 triệu người, với độ tuổi trung bình hơn 30, trong đó chủ yếu là thế hệ Millennials (những người sinh năm 1980 đến 2000, cuộc sống gắn liền với internet), nền kinh tế internet của Việt Nam đang nắm giữ tiềm năng phát triển rất lớn. Việt Nam có tỉ lệ phổ cập di động rất cao (trên $145 \%$ ) nhưng người Việt thích dùng điện thoại để vào mạng xã hội (46\%) và tìm kiếm nội dung (45\%) hơn là tiến hành các giao dịch ngân hàng (4\%), Có 24,6 triệu người sử dụng smartphone và 25 giờ/tuần là số giờ dùng internet trung bình mỗi tuần của một người, tỷ lệ sử dụng tiền mặt lên tới 90\%. Tầng lớp trung lưu tại Việt Nam đang tăng lên, ước tính đến năm 2020 sẽ lên tới con số 33 triệu người, và đây là tốc độ tăng ước tính cao nhất Đông Nam Á. Một yếu tố nữa là tại Việt Nam tỉ lệ người dùng thẻ ATM cũng thấp và chủ yếu có thói quen tiêu tiều mặt. Vì vậy, Việt Nam được coi là một thị trường tiềm năng trong lĩnh vực phát triển và áp dụng công nghệ số, đặc biệt trong lĩnh vực thanh toán điện tử khi Chính phủ và Ngân hàng Nhà nước Việt Nam đang khuyến khích người dân hạn chế dùng tiền mặt. (Minh Tuyết, 2015)

Fintech tại Việt Nam vẫn còn đang trong giai đoạn đầu phát triển với phần lớn trong đó tập trung vào mảng thanh toán. Có thể kể ra các công ty khởi nghiệp Fintech tiêu biêu như công cụ thanh toán trực tuyến như Payoo, VinaPay, OnePay, MoMo... hoặc giải pháp thanh toán kỹ thuật số POS/MOS như iBox, Moc... Bên cạnh những đại diện trên, Việt Nam còn có một số startup hoạt động ở mảng khác như gây quỹ cộng đồng (FundStart, Comicola, Betado hay Firststep); LoanVi với dịch vụ cho vay trực tuyến; quản lý dữ liệu tài chính cá nhân với BankGo, MoneyLover, Mobivi; ngân hàng kỹ thuật số đầu tiên của Việt Nam với Timo. Từ đó có thể thấy sự phát triển của Fintech tại Việt Nam cũng sôi động không kém bất kỳ quốc gia nào trên thế giới.

Khung khổ pháp lý quản lý của Việt Nam về cơ bản mới chỉ đáp ứng được một phần cho lĩnh vực công nghệ tài chính trong thanh toán, chưa có khung khổ pháp lý đầy đủ, đồng bộ cho các lĩnh vực tài chính khác. Trong bối cảnh các quốc gia trong khu vực và trên thế giới có những cách tiếp cận khác nhau trong việc hỗ trợ và thúc đẩy phát triển của các doanh nghiệp Fintech, Thống đốc NHNN đã ban hành Quyết định số 328/QĐ-NHNN ngày 16/3/2017 thành lập Ban Chỉ đạo và Tổ giúp việc về lĩnh 
vực Fintech của NHNN. Theo đó, Ban Chỉ đạo có nhiệm vụ tham mưu đề xuất Thống đốc nhằm xây dựng hệ sinh thế, cơ chế quản lý phù hợp, hoàn thiện khung khổ pháp lý, tạo thuận lợi cho các doanh nghiệp Fintech của Việt Nam ra đời và phát triển, đồng thời xây dựng chiến lược và kế hoạch phát triển Fintech tại Việt Nam phù hợp với chủ trương, định hướng của Chính phủ. (Nguyễn Kim Anh, 2017).

\subsubsection{Hợp tác giũa Fintech và các định chế tài chính truyền thống sẽ là xu huoóng không thể tránh} khỏi

Chúng tôi cho rằng những lo lắng về tác động tiêu cực tiềm năng ngân hàng lên các công ty khởi nghiệp FinTech đã dần qua đi và các ngân hàng hiện tại đang tích cực tìm kiếm cơ hội hợp tác với các công ty FinTech. Các ngân hàng đã sử dụng nhiều kênh khác nhau như các chương trình vườn ươm khởi nghiệp hoặc thậm chí là đầu tư vào các công ty Fintech như là một cách thức để kiểm soát các công nghệ của FinTech. Từ đó các ngân hàng theo dõi bất kỳ công nghệ mới nổi nào có thể được tích hợp trong ngân hàng, cũng như tìm kiếm các cơ hội cho lợi nhuận cao. Hầu hết các ngân hàng toàn cầu đã bắt đầu các sáng kiến như vậy của FinTech, và các ngân hàng nhỏ hơn và khu vực đang bắt đầu triển khai các chương trình tương tự và tạo ra các hệ sinh thái. Các ngân hàng cũng sẽ sử dụng các công nghệ này để chủ động đi theo các thị trường thường khó nắm bắt do chi phí cao. Các vùng nông thôn và vùng sâu vùng xa có thể được khai thác với sự trợ giúp của công nghệ, và thế hệ trẻ với khả năng nắm bắt được mức độ phức tạp về công nghệ cao có thể là mục tiêu được nhắm tới với các dịch vụ thích hợp. Các ngân hàng được kỳ vọng sẽ tiếp tục làm việc chặt chẽ với các doanh nghiệp mới thành lập để đổi mới nhanh hơn và tạo ra những ưu đãi có thể cải thiện trải nghiệm của khách hàng và mở rộng các điểm tiếp xúc của khách hàng, từ đó nâng cao lòng trung thành của họ.

Chúng tôi cũng đưa ra kiến nghị mô hình cũ cũng nên thừa nhận những yếu tố tích cực và vai trò của Fintech trong việc bổ sung những khoảng trống dịch vụ mà mô hình truyền thống không đáp ứng đủ và kịp thời cho người tiêu dùng. Theo quy định của ngành ngân hàng về đảm bảo an toàn tín dụng, nhiều trường hợp khách hàng tiềm năng nhưng do không đáp ứng được các tiêu chuẩn tín dụng khắt khe của ngân hàng truyền thống nên đã dẫn tới việc bị từ chối cấp tín dụng. Hệ quả là họ phải tìm đến các lựa chọn khác như cầm đồ, tín dụng đen ... với lãi suất "cắt cổ".

Với những ưu điểm không thể phủ nhận của Fintech ở việc đáp ứng nhu cầu của người tiêu dùng trong những lĩnh vực có quy mô vốn nhỏ và rủi ro cao như cho vay tiêu dùng hay thanh toán trực tuyến, Fintech vẫn bị hạn chế trong việc tiếp cận đến các dịch vụ truyền thống của ngân hàng như cho vay mua nhà, cho vay doanh nghiệp lớn. Ngược lại, ngành ngân hàng lại có thế mạnh về nguồn vốn, về thông tin khách hàng và tuân thủ tốt hành lang pháp lý cho hoạt động tín dụng nói riêng và ngân hàng nói chung. Vi vậy mối quan hệ giữa Fintech và các định chế tài chính truyền thống như ngân hàng nên đi theo hướng cộng hưởng và hợp lực. Từ đó Fintech sẽ có tác động cả về số lượng lẫn biến đổi trong dài hạn với các dịch vụ tài chính. Fintech có thể giúp tối ưu hóa cấu trúc chi phí trong ngành tài chính, giúp các ngân hàng mở rộng diện tiếp cận với khách hàng có tiềm năng doanh thu thấp hơn.

Một điểm khá thú vị từ nghiên cứu của nhóm tác giả Hoàng Hà, Trần Đình Uyên (2017) về cho vay ngang hàng online (P2PL) - một sản phẩm của Fintech, cho thấy khi được hỏi mô hình mới này liệu có là cơ hội đối với ngành ngân hàng truyền thống thì có $51 \%$ người được hỏi đồng ý với nhận định trên, trong khi chỉ có $11,6 \%$ không đồng ý.

\section{2. Đánh giá}

Trong nghiên cứu của Christian Haddad, Lars Hornuf (2016), nhóm tác giả nhận thấy sự phát triển của Fintech có liên quan đến sự lành mạnh của thị trường tài chính theo chiều hướng ngược, cụ thể ở các quốc gia phát triển có thị trường tài chính lành mạnh, số lượng các công ty khởi nghiệp 
fintech sẽ ít hơn các quốc gia vốn có nền tài chính gặp nhiều vấn đề. Chúng tôi cho rằng đây là nhận định hoàn toàn có cơ sở. Thực tế đã chứng minh như tại Trung Quốc, số lượng các công ty Fintech đang gia tăng với một tốc độ chóng mặt và các nhà quản lý của nước này hiện đã phải áp dụng nhiều chính sách thắt chặt quản lý với mô hình mới này. Thêm một lý do để giải thích cho quan điểm trên là tại các quốc gia có nền tài chính chưa hoàn thiện, đặc biệt là các nước đang phát triển, trong đó có Việt Nam, sẽ tồn tại nhiều kẻ hở pháp lý, các start-up vốn rất nhanh nhạy và có lợi thế về công nghệ sẽ nhanh chóng tìm ra và lấp đầy khoảng trống của thị trường hình thành nên bởi các kẻ hở này.

Nghiên cứu về tác động của Fintech lên thị trường tài chính và các định chế tài chính truyền thống đã làm rõ việc Fintech đã và đang tạo ra những thách thức rất lớn đối với các định chế tài chính truyền thống. Các định chế này đã và đang hoạch định lại các chính sách của mình nhằm thích ứng với cuộc $\mathrm{CMCN}$ 4.0. Nhiều sản phẩm mới cũng được đưa ra để cạnh tranh với Fintech như ngân hàng như ngân hàng online, thanh toán trên di động... Ngoài ra với ưu thế công nghệ của mình, các Fintech cũng gây nên một áp lực rất với ngân hàng trong việc giảm dần các chi nhánh và tinh gọn đội ngũ nhân viên, quản lý.

Trong một nghiên cứu khác tại Việt Nam, nhóm tác giả Phạm Xuân Hòe (2017) đã thực hiện khảo sát với các ngân hàng. Kết quả cho thấy $100 \%$ ngân hàng khẳng định đều có kế hoạch mở rộng các cơ hội hợp tác với các công ty Fintech trong tương lai. 92\% ngân hàng mong muốn mở rộng hợp tác với các công ty Fintech trong lĩnh vực thanh toán, $76 \%$ dự định hợp tác về dịnh vụ internet banking, $68 \%$ có nhu cầu hợp tác để nghiên cứu và dữ liệu tài chính (bao gồm dữ liệu lớn - big data), 64\% dự định hợp tác trong lĩnh vực cho vay, 60\% trả lời muốn hợp tác với các công ty Fintech để phát triển kiều hối và tài chính cá nhân, $36 \%$ dự định hợp tác để mở rộng đầu tư và $16 \%$ có chiến lược hợp tác để đầu tư chứng khoán hay Blockchain và tiền ảo.

Từ đó chúng ta có thể khẳng định mô hình hợp tác giữa Fintech và ngân hàng trong tương lai có thể giúp cho việc giao dịch tài chính được thực hiện dễ dàng trên nên tảng công nghệ cao, từ đó ngân hàng càng trở nên thông minh và phục vụ khách hàng tốt nhất. Một khi được liên kết với nhau, thời gian giao dịch và chi phí cho các loại hình dịch vụ sẽ giảm xuống, cạnh tranh lúc này sẽ phát huy vai trò tích cực đối với khách hàng.

\section{Kết luận}

Tóm lại, trong bối cảnh $\mathrm{CMCN} 4.0$ diễn ra mạnh mẽ trên nhiều lĩnh vực thì sự phát triển sâu rộng của các công ty công nghệ tài chính Fintech trên thế giới và Việt Nam là một biểu hiện sinh động của trào lưu trên, tạo ra khả năng tăng cường tiếp cận dịch vụ ngân hàng - tài chính, gia tăng giá trị cho khách hàng sử dụng dịch vụ. Do được phát triển trên nền tảng hệ thống công nghệ thông tin và viễn thông không cần mạng lưới chi nhánh và phòng giao dịch rộng khắp như ngân hàng, mà các sản phẩm, dịch vụ do doanh nghiệp Fintech cung ứng đã và đang thu hút được một số lượng lớn khách hàng, đặc biệt là người dân sống ở vùng nông thôn, vùng sâu, vùng xa, hải đảo khó tiếp cận với dịch vụ ngân hàng.

Có thể khẳng định sự phát triển của Fintech đã mang lại nhiều thay đổi mạnh mẽ trong thế giới tài chính. Thế hệ công ty khởi nghiệp mới này vừa tạo ra những thách thức nhưng đồng thời cũng mang lại nhiều cơ hội cho các định chế tài chính truyền thống, trong đó có ngân hàng. Việc tìm ra tiếng nói chung cũng có nhiều rao cản cả về chính sách, quy định quản lý, cơ sở hạ tầng và dịch vụ Chính phủ. Vì vậy, muốn thúc đẩy Fintech, các bên tham gia cần chấp nhận đột phá, nhất là các cơ quan lập pháp cần quan tâm và đưa ra những quy định phù hợp, vừa giảm thiểu các rủi ro có thể gây ra bởi các công ty Fintech cho toàn bộ thị trường nhưng cũng hỗ trợ sự phát triển và đảm bảo sự cạnh 
tranh công bằng giữa Fintech và các định chế tài chính truyền thống. Chỉ khi đó lợi ích của mô hình mới này mang lại cho cả mô hình cũ - với thế mạnh về uy tín, sự bảo đảm của chính quyền và mô hình mới - với thế mạnh về công nghệ, sáng tạo và dịch vụ sẽ ngày càng đi lên theo tinh thần Win-win và quyền lợi của khách hàng sẽ được quan tâm và đáp ứng đầy đủ hơn.

Hoang Ha has broad international work experience, including time in France as Treasury Executive of Conforama. His research interests are in Behavioral Finance, Capital Budgeting, Entrepreneurship...He has also been a visiting scholar at St. Ambrose University, Iowa, United States.

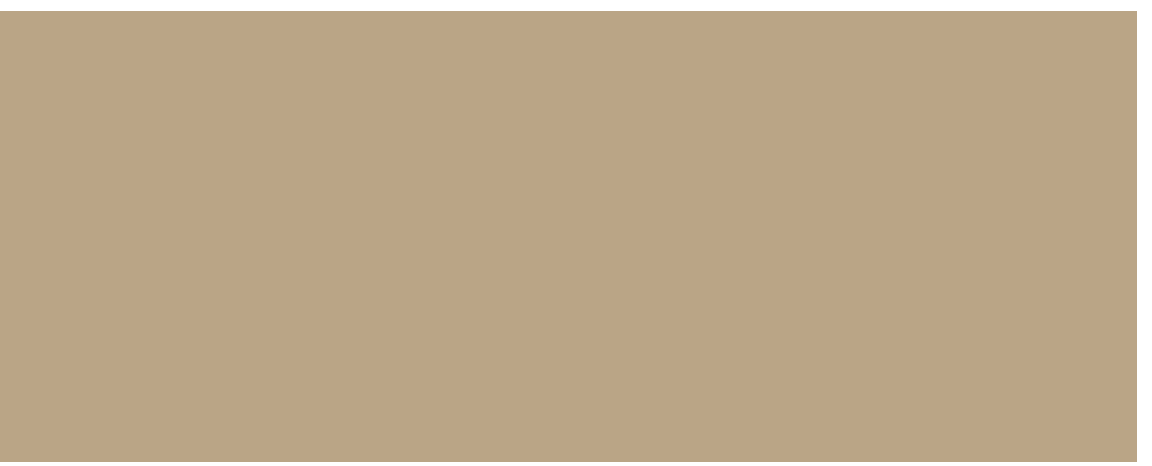




\section{REFERENCES}

[1] Kagermann, H., Helbig, J., Hellinger, A., \& Wahlster, W. (2013). Recommendations for implementing the strategic initiative INDUSTRIE 4.0: Securing the future of German manufacturing industry; final report of the Industrie 4.0 Working Group. Forschungsunion.

[2] Schwab, K. (2017). The fourth industrial revolution. Crown Business.

[3] Stock, T., \& Seliger, G. (2016). Opportunities of sustainable manufacturing in industry 4.0. Procedia Cirp, 40, 536-541.

[4] Tư Giang (2017). Khi Cách mạng công nghiệp 4.0 xồng xộc đến, Thời Báo kinh tế Sài Gòn.

[5] Phạm Xuân Hòe và đồng tác giả (2017). 10 nhận định về ngân hàng Việt Nam với Cách mạng công nghiệp 4.0. Tạp chí ngân hàng số 13.

[6] Chỉ thị 16 (2017). Về việc tăng cường năng lực tiếp cận cuộc cách mạng công nghiệp lần thứ 4, Thủ tuoóng Chính phủ.

[7] Lin, T. C. (2015). Infinite Financial Intermediation. Wake Forest L. Rev., 50, 643.

[8] Trần Thị Hiền Dung (2014). Nghiên cứu sự hài lòng của khách hàng đối với dịch vụ cho vay tiêu dùng tại ngân hàng tmcp dầu khí toàn cầu. Luận Văn Thạc sỹ, Đại học Kinh tế Đà Nẵng.

[9] Minh Tuyết (2015). Mobile marketing forum on way. Vietnam Economic Times.

[10] Nguyễn Kim Anh (2017). Fintech - Xu hướng phát triển và khuyến nghị đối với NHNN. Ngân hàng Nhà nước Việt Nam

[11] Lucinda Shen (2016). Here's Why Bank of America Is Slashing Up to 8,400 Jobs. Fortune Finance

[12] Haddad, C., \& Hornuf, L. (2016). The emergence of the global fintech market: Economic and technological determinants.

[13] Manyika, J., Lund, S., Singer, M., White, O., \& Berry, C. (2016). Digital Finance for All: Powering Inclusive Growth In Emerging Economies. McKinsey Global Institute.

[14] Uyen, T. D., \& Ha, H. (2017). The sharing economy and collaborative finance: The case of P2P lending in Vietnam. Jurnal Ilmiah Ekonomi Bisnis, 22(2).

[15] Balyuk, T. (2016). Financial Innovation and Borrowers: Evidence from Peer-to-Peer Lending.

[16] Phạm Xuân Hòe và đồng tác giả (2017). Start-up của Fintech, cơ hội hợp tác và thách thức cạnh tranh với ngân hàng. Tạp chí ngân hàng số 14. 